\title{
Impact of oral contraceptives on periodontal health
}

\author{
Sharma Prachi ${ }^{1}$, Solanki Jitender ${ }^{1}$, Choudhary Rahul ${ }^{2}$, Khetan Jitendra ${ }^{3}$, Mishra Priyanka ${ }^{1}$, Shah Disha ${ }^{4}$
}

1. Department of Public Health Dentistry, Rajasthan Dental College and Hospital, Jaipur.

2. Department of Pedodontics, Vyas Dental College and Hospital, Jodhpur.

3. Department of Prosthodontics, NIMS, Jaipur.

4. Department of Public Health Dentistry, Pacific Dental College and Hospital, Udaipur.

\section{Emails:}

Prachi Sharma: sharmaprachi810@gmail.com; Jitender Solanki: solankijitender@gmail.com; Rahul Choudhary: rahulchoudhary13@yahoo.com; Jitendra Khetan:: khetan2jit@gmail.com; Priyanka Mishra: priyankamishra8113@gmail. com; Disha Shah: yamsdi@gmail.com

\begin{abstract}
Background: Oral contraceptives pills (OCPs) are common and a convenient form of contraception. The use of hormonal contraceptives by women has been considered to influence gingival and periodontal disease progression.

Aim: This study was conducted to assess the effect of oral contraceptive pills on the periodontal health.

Materials and method: A cross-sectional comparative study was conducted among 200 females aged 18 years and above of Jaipur city. The study subjects were divided into two groups i.e. contraceptive users and non-contraceptive users, each group consisted 100 females. Data was collected using Modified WHO Performa (1997). Periodontal status was examined using Community Periodontal Index (CPI) and Loss of Attachment (LOA). Chi-square test and one sample t-test was used for statistical analysis and $\mathrm{P}$ value was set $(\mathrm{p}<0.05)$ as significant.

Results: Mean CPI score in subjects and non-contraceptive users was 2.34+ 0.81 and 1.16+0.89 respectively. Mean LOA score in each group was $0.28+0.45$ and $0.19+0.50$ respectively.

Conclusion: Oral Contraceptive pills had adverse effects on periodontal health.

Keywords: Oral contraceptive, community periodontal index, loss of attachment, periodontal health.

DOI: https://dx.doi.org/10.4314/ahs.v19i1.56

Cite as: Prachi S, Jitender S, Rahul C, Jitendra K, Priyanka M, S D. Impact of oral contraceptives on periodontal health. Afri Health Sci. 2019;19(1). 1795-1800. bttps:// dx.doi. org/10.4314/ abs. v19i1.56
\end{abstract}

\section{Introduction}

Oral cavity is the mirror of general health and the target organ for number of adverse reactions that arise due to side effects of medications ${ }^{1}$. The initiation of contracep-

\section{Corresponding author: \\ Jitender Solanki, Department of Public health dentistry RajasthanDental College and Hospital, Bargu khurd, Near toll plaza, Ajmer road, Jaipur, Rajasthan. Pin-302026 \\ Mobile No.: +919571580558 \\ Mail Id: solankijitender@gmail.com}

tives created interest in their effect on oral and periodontal tissues in the late 1960's and 1970's². Many studies had linked the use of oral contraceptive (OC) to increased gingival inflammation ${ }^{3,4}$ and some suggested that periodontal attachment loss is likely to occur in contraceptive users $^{5,6}$.

Women are more sensitive to oral health problems because of the hormonal changes they experience during their lifetime. These hormonal changes not only affect the general health but also the oral health. There are five stages in a women's life during which changes in hormone levels make them more susceptible to oral health 
problems - puberty, monthly menstruation cycle, use of oral contraceptives, pregnancy, and menopause ${ }^{7}$.

Current oral contraceptives consist of low doses of estrogens $(0.05 \mathrm{mg} /$ day) and progestin $(1.5 \mathrm{mg} /$ day). Oral contraceptive agents are one of the most commonly used classes of drugs by females. The number of women on oral contraceptives has reached approximately 50 million worldwide, as a result of such widespread use; many systemic and oral side effects have been identified. ${ }^{1}$ The systemic side effects include- nausea, vomiting, diarrhea, stomach cramps, weight loss, acne, breast tenderness, skin pigmentation changes in menstrual flow etc ${ }^{8}$.

There are many Studies which show the negative effects of oral contraceptives on periodontal health ${ }^{9-10}$. The two possible factors influencing the effects of oral contraceptive pills (OCP's) on periodontal condition include dosage and the duration of intake of the pills. A continued exposure of OCP use results in a higher risk of periodontal disease, it can be due to increased production of pro-inflammatory cytokines and prostaglandins from elevated levels of these hormones ${ }^{11}$.

Studies have shown that females who use oral contraceptives have higher prevalence of gingival inflammation, loss of attachment and periodontal disease progression3-5,9-10. However, recent studies based on large or small population suggested that current combined oral contraceptives (COC) do not affect periodontal health, possibly related to lower level of progesterone and estradiol than previously used medications ${ }^{12-14}$.

However, there is a need to reassess the impact of contemporary oral contraceptives on periodontal health. The present study was an attempt to assess the impact of oral contraceptives on periodontal health.

\section{Materials and method}

This comparative cross-sectional study was conducted among 200 females aged 18 years and above. The study subjects were selected by convenient sampling technique and categorized into two groups. Group A included 100 female subjects who were taking OC pills while group B includes 100 females who had no history of taking OC pills. During the period of two months out of all the females visiting the health centers, sub-centers and hospitals, females fulfilling the inclusion and exclusion criteria were selected. The subject's selection was done till the desired sample size was reached

\section{Inclusion criteria}

1. Subjects who were above 18 years of age.

2. Subjects who were married

3. Subjects who had no history of pregnancy

\section{Exclusion criteria}

1. Those who consumed alcohol and tobacco in any form 2. Medically compromised.

3. Those who were under any type of medications other than OCP.

4. Those who had periodontal problem

5. Those who had undergone any periodontal treatment prior to 6 months of study.

Visits to the selected health centers, sub-centers and hospitals were made after obtaining the permission from concerned authorities. Ethical approval was obtained from the institutional ethical committee to carry out the study. Informed verbal consent was obtained prior to the data collection. Data was collected using modified WHO proforma (1997) which includes demographic details and Community Periodontal Index (CPI) and Loss of Attachment (LOA) index. The information regarding oral hygiene habits and duration of oral contraceptive pills was also recorded. Oral examination was carried out using Mouth mirror, and CPITN probe. 


\begin{tabular}{|l|l|}
\hline $\mathbf{0}$ & Healthy \\
\hline $\mathbf{1}$ & Bleeding On Probing \\
\hline $\mathbf{2}$ & Calculus detected, but all the black band visible \\
\hline $\mathbf{3}$ & Pocket 4-5 (gingival margin within black band visible) \\
\hline $\mathbf{4}$ & Pocket 6mm or more (Black band not visible) \\
\hline $\mathbf{X}$ & Excluded sextant \\
\hline $\mathbf{9}$ & Not recorded \\
\hline
\end{tabular}

\section{Loss of attachment:}

- Helps us obtain an estimate of the lifetime accumulated destruction

- Most reliable way of examining for loss of attachment in each sextant is to record this immediately after recording the CPI score for that particular sextant

- Pocket depth gives some idea of loss of attachment but is unreliable when there is gingival recession.

\section{Scoring}

\section{criterion for CPI}

\begin{tabular}{|c|l|}
\hline 0 & $\begin{array}{l}\text { Loss of attachment } 0-3 \mathrm{~mm} \text { (CEJ not visible \& CPI score 0-3 } \\
\text { If the CEJ is not visible \& the CPI score is 4, or if the CEJ is visible }\end{array}$ \\
\hline 1 & Loss of attachment is 4-5mm(CEJ within the black band \\
\hline 2 & $\begin{array}{l}\text { Loss of attachment is } 6-8 \mathrm{~mm}(\mathrm{CEJ} \text { between the upper limit of the black } \\
\text { band \& the } 8-5 \mathrm{~mm}\end{array}$ \\
\hline 3 & Loss of attachment 9-12mm(CEJ between the $8.5 \mathrm{~mm} \mathrm{\&} \mathrm{11.5mm} \mathrm{rings}$ \\
\hline 4 & Loss of attachment $12 \mathrm{~mm}$ or more \\
\hline $\mathrm{X}$ & Excluded sextant (Less than two teeth present \\
\hline 9 & Not recorded (CEJ neither visible nor detectable) \\
\hline
\end{tabular}




\section{Statistical analysis}

Data thus obtained was entered in Microsoft excel sheet 2007 and subjected for statistical analysis using SPSS 20.0.0 version. Chi-square and one sample t-test were used for statistical analysis. Level of significance was set at $\mathrm{p}<0.05$ as significant.

\section{Results}

The present comparative cross-sectional study was con- ducted among randomly selected 200 females aged 18 years and above. The mean age was $26.37 \& 27.08$ years for group A and B respectively

Mean CPI score in group A and B was 2.34+ 0.81 and $1.16+0.89$ respectively. Mean LOA score in group A and $\mathrm{B}$ was $0.28+0.45$ and $0.19+0.50$ respectively.

Table I. On applying one sample t-test the mean difference of CPI and LOA was 1.75 and 0.235 respectively which was found highly statistical significant $(p=0.00)$ for both the groups.

\section{Table I Mean difference between CPI and LOA in both the groups}

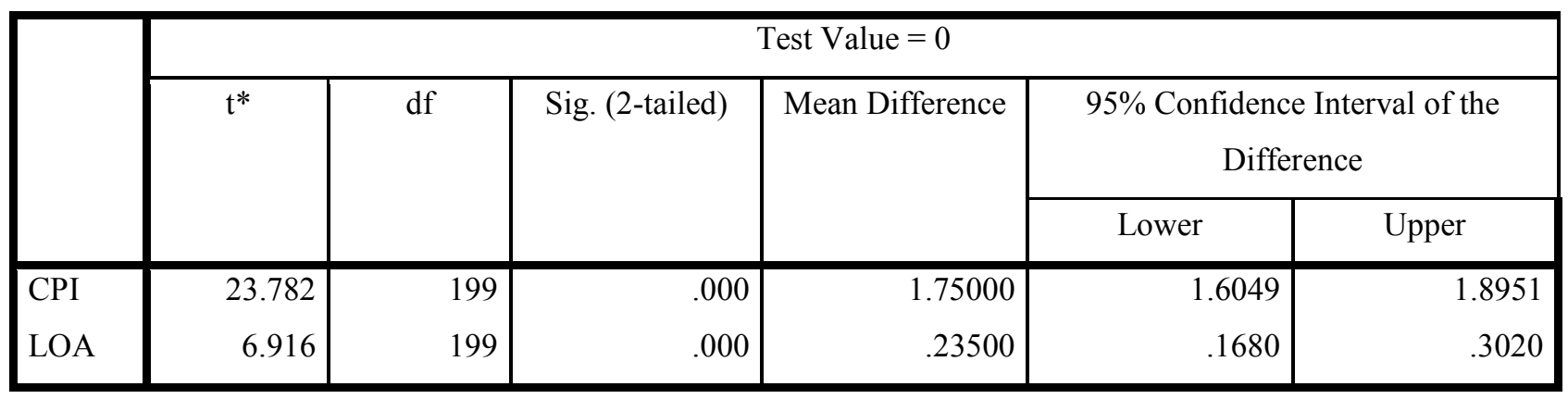

*One-Sample t-Test

Table II depicts the association of periodontal status (CPI) and duration of intake of oral contraceptive pills. Bleeding on probing was observed highest $(62.5 \%)$ in 8 months while calculus was observed highest $(100 \%)$ in 9 and 15 months. Periodontal pocket (4-5mm) was found highest $(100 \%)$ in 18 months while periodontal pocket (6-8 mm) was observed highest (18.75\%) in 36 months. A Highly significant association was observed among CPI and duration of intake of OCP $(\mathrm{P}=0.000)$ which shows that more the duration of OC intake, poorer is the periodontal health of the subjects.

Table II- Effect of oral contraceptive on periodontal health (CPI) with duration of OCP use.

\begin{tabular}{|c|c|c|c|c|c|c|c|c|c|c|c|}
\hline & & & & uration of $i$ & ake (Mont & & & & & \multirow[b]{2}{*}{$\mathbf{x 2 ^ { * }}$} & \multirow[b]{2}{*}{$P^{\# \#}$ value } \\
\hline & 6.00 & 8.00 & 9.00 & 12.00 & 15.00 & 18.00 & 24.00 & 36.00 & Total & & \\
\hline Healthy & $0(0.00 \%)$ & $0(0.00 \%)$ & $0(0.00 \%)$ & $3(8.82 \%)$ & $0(0.00 \%)$ & $0(0.00 \%)$ & $0(0.00 \%)$ & $0(0.00 \%)$ & 3 & \multirow[t]{3}{*}{75.11} & \multirow[t]{3}{*}{0.00} \\
\hline BOP*** & $1(33.33 \%)$ & $5(62.5 \%)$ & $0(0.00 \%)$ & $4(11.76 \%)$ & $0(0.00 \%)$ & $0(0.00 \%)$ & $0(0.00 \%)$ & $0(0.00 \%)$ & 10 & & \\
\hline Calculus & $2(66.66 \%)$ & $3(37.5 \%)$ & $7(100 \%)$ & $8(23.5 \%)$ & $2(100 \%)$ & $0(0.00 \%)$ & $12(42.85 \%)$ & $6(37.5 \%)$ & & & \\
\hline
\end{tabular}


Table III shows the association of periodontal status (LOA) and duration of intake of oral contraceptive pill. Loss of attachment (0-3mm) was observed highest
$(100 \%)$ in 6, 8,9,15 and 18 months. Loss of attachment (4-5 mm) was observed highest $(68.75 \%)$ in 36 month. A highly significant association was observed between LOA and duration of intake of OCP $(\mathrm{P}=0.000)$.

\section{Table III- Effect of oral contraceptive on periodontal health (LOA) with duration of OCP use.}

\begin{tabular}{|c|c|c|c|c|c|c|c|c|c|c|c|}
\hline & \multicolumn{8}{|c|}{ Duration of intake } & \multirow[b]{2}{*}{ Total } & \multirow[b]{2}{*}{$\mathbf{x} 2 * *$} & \multirow{2}{*}{$\begin{array}{l}\mathbf{p}^{\#} \\
\text { value }\end{array}$} \\
\hline & 6.00 & 8.00 & 9.00 & 12.00 & 15.00 & 18.00 & 24.00 & 36.00 & & & \\
\hline 0-3mm & 3 & 8 & 7 & 29 & 2 & 2 & 16 & 5 & 72 & \multirow[t]{6}{*}{27.78} & \multirow{6}{*}{$\begin{array}{l}0.00 \\
\text { (HS) }\end{array}$} \\
\hline & $(100 \%)$ & $(100 \%)$ & $(100 \%)$ & $(85.29 \%)$ & $(100 \%)$ & $(100 \%)$ & $(57.14 \%)$ & $(31.25 \%)$ & & & \\
\hline \multirow{4}{*}{$\begin{array}{l}\text { 4-5mm } \\
\text { (cementoen } \\
\text { amel } \\
\text { junction } \\
\text { (CEJ) } \\
\text { within } \\
\text { black band) }\end{array}$} & & & 0 & & 0 & 0 & 12 & 11 & 28 & & \\
\hline & $(0.00 \%)$ & $(0.00 \%)$ & $(0.00 \%)$ & $(14.7 \%)$ & $(0.00 \%)$ & $(0.00 \%)$ & $(42.85 \%)$ & $(68.75 \%)$ & & & \\
\hline & 3 & 8 & 7 & 34 & 2 & 2 & 28 & 16 & 100 & & \\
\hline & $(100 \%)$ & $(100 \%)$ & $(100 \%)$ & $(100 \%)$ & $(100 \%)$ & $(100 \%)$ & $(100 \%)$ & $(100 \%)$ & & & \\
\hline
\end{tabular}

${ }^{*} \mathrm{LOA}=$ Loss of attachment, ${ }^{*} \mathrm{x} 2=$ Chi-square test, ${ }^{*} \mathrm{p}<0.05$ (significant), HS= highly significant

\section{Discussion}

There have been several studies concerning the effect of oral contraceptives on the gingiva and periodontal tissues. The elevated ovarian hormones could predispose women to increased gingival inflammation and periodontal destruction. Both estrogen and progesterone are known to cause increased gingival exudates, edema and inflammation $^{15}$.

Oral contraceptives (OCs) enhance periodontal breakdown by reducing the resistance to dental plaque and can induce gingival enlargement in otherwise healthy females $^{15,2}$. The long term use of OC may cause clinical attachment loss (CAL), in $\neg$ creased gingival inflammation and gingival enlargement ${ }^{2,16,17}$.

In the present study it was found that the women who are consuming oral contraceptives for 1 and a half to 2 years had bleeding on probing, deeper periodontal pocket depth, calculus and significant attachment loss. This indicates that the longer the duration of $\mathrm{OC}$ intake, the poorer is the periodontal health. Studies conducted by Tilakaratne $\mathrm{A}$ et $\mathrm{al}^{18}$ and GM knight ${ }^{19}$ showed that the mean
LOA was high among women who had used OC between 2 to 4 years which means they had poor periodontal health. Similarly in the study done by CL Pankhurst et $\mathrm{al}^{20}$ it was found statistically significant gingival inflammation after longer periods of medication $\quad(p<0.001)$. Study conducted by Taichamn $\mathrm{LS}^{13}$ showed that OC users had mild gingivitis but there was no significant association found in relation to periodontal status.

Oral contraceptives have pronounced effects on gingival microvasculature and it has been shown that human gingiva contains receptors for progesterone and estrogen. Hormonal dosage and duration of intake are the possible factors which influence the effect of $\mathrm{OC}$ on the periodontal condition. A continued exposure of OCP for longer duration results in higher risk of periodontal disease development due to increased production of pro-inflammatory cytokines and prostaglandins as a result of elevated levels of the hormones ${ }^{7,9,21}$.

In the study we found that among the females who are non-contraceptive users, some of them had good periodontal health while some of them had poor periodontal health this can be due to various other reasons such as 
inadequate knowledge about oral hygiene aids, inadequate oral hygiene practices and improper diet.

\section{Conclusion}

Females on contraceptives for longer duration had higher pocket depth, gingival bleeding and attachment loss as compared to the non-contraceptive user group. Contraceptive users had poor periodontal and gingival health. A comprehensive medical history and assessment of vital signs are extremely important in this group of patients. Treatment of gingival and periodontal inflammation exaggerated by oral contraceptives should include establishing an oral hygiene program. As OC pills have poor effect on oral health, females should use other measures of birth control.

\section{Financial support}

Nil

\section{Acknowledgement}

We are thankful to all the study participants.

\section{Conflict of interest}

None.

\section{References}

1. Reddy P, Jamadar S, Chaitanyababu N. Effects of Oral contraceptives on the oral cavity. Indian Journal of Dental Advancement. 2013;5(3):1274-6.

2. Mariotti A. Sex steroid hormones and cell dynamics in the periodontium. Crit Rev Oral Biol Med. 1994;5:27-53.

3. Aklkwarf KL. Effect of oral contraceptive therapy on gingival inflammation in humans. $J$ Periodontol. 1978;49(11):560-3.

4. Abdollahi M, Rahimi R, Radfar M. Current Opinion on drug-induced oral reactions: A comprehensive review. J Contemp Dent Pract. 2008;9(3):1-15.

5. Das AK, Bhowmick S, Dutta A. Oral contraceptives and periodontal disease- its prevalence and severity. J Indian Dent Assoc. 1971;43(8):155-8.

6. Amar S, Chung KM. Influence of hormonal variation on the periodontium in women. Periodontology. 2000 1994;6:79-87.

7. https:// my.Clevelendclinic.org/ (cited on 29 jan. 2016)

8. Speckman I, Diaz R, Molina R, Marcuschamer E, Hawley C.A lifetime of normal hormonal events and their impact on periodontal Health. Perinatol Reprod Hum. 2009;23(2):53-64.
9. Mealey L, Moritz J. Hormonal influences on periodontium. Periodontol. 2003;32:59-81.

10. Haerian Ardakani A, Moeintaghavi A, Talebi- Ardakani MR, Sohrabi K, Bahami S, Dargahi M. The association between current low-dose oral contraceptive pills and periodontal health: a matched-case-control study. $J$ Contemp Dent Pract. 2010;11(3):033-40.

11. Domingues R, Ferraz B, Greghi S, Rezende M, Passanezi E, Santana A. Influence of combined oral contraceptives on the periodontal condition. J App Oral Sci. 2012;20(2):253-9.

12. Preshaw PM, Knutsen MA, Mariotti A. Experimental gingivitis in women using oral contraceptives. J Dent Res. 2001;80:5-11. PubMed.

13. Taichman LS, Eklund SA. Oral contraceptives and periodontal diseases: rethinking the association based upon analysis of National Health and Nutrition Examination Survey data. J Periodontol. 2005;76:1374-5. PubMed.

14. Mullally BH, Coulter WA, Hutchinson JD, Clarke HA. Current oral contraceptive status and periodontitis in young adults. J Periodontol. 2007;78:1031-6. PubMed.

15. Mascarenhas P, Gapski R, Al-Shammari K, Wang H-L. In $\neg$ fluence of sex hormones on the periodontium. J Clin Periodontol. 2003;30:671-81.

16. Palmer R, Soory M. Modifying Factors. In: Lindhe J, Lang NP, Karring T. Ed. Clinical Periodontology and Implant Dentistry, 5thEd. Oxford,USA:, Blackwell Munksgaard; 2008.307-27.

17. Nassrawin NA, Al- Najdawi WA, Shakkoury WA. The effects of the oral contraceptive pill on the gingival and periodontal health. J. R. Nav. Med. Serv. 2010;17(1):79.

18. Tilakaratne A, Soory M, Ranasinghe AW, Corea SMX, Ekanayake SL, De SilvaM. Effects of hormonal contraceptives on the periodontium, in a population of rural Sri-Lankan women. J Clin Periodontol. 2000;27:753-7. PubMed.

19. GM Knight, A Bryan Wade: The effects of hormonal contraceptives on the human periodontium. J. Periodont Res. 1973;9:18-22. PubMed.

20. C L Pankhurst, I M Waite, K A Hicks, Y Allen f, R. D. Harknessf: The Influence of Oral Contraceptive Therapy on the Periodontium-Duration of Drug Therapy. J. Periodontol. 1981;52(10):253-9. PubMed.

21. Mistry S, Bhowmick D. Oral contraceptive pill induced periodontal endocrinopathies and its management: A case report. Eur J Den. 2012;6(3):324-9. 